\title{
Europa am energiepolitischen Wendepunkt
}

Europa - und damit auch Österreich - steht an einem energiepolitischen Wendepunkt. Der Kontinent braucht im Laufe der kommenden drei Jahrzehnte einen gewaltigen elektrizitätswirtschaftlichen Investitionsschub: Es ist gleichsam der gesamte Kraftwerkspark zu erneuern, und die transeuropäischen Netze sind auf ein modernes, effizienteres Niveau auszubauen. Nur so wird man die Stromversorgung, das Rückgrat unserer modernen Gesellschaft, dauerhaft sichern können.

Das ist die Vision, die sich in den Köpfen verantwortungsvoller Entscheidungsträger festzusetzen beginnt. Langsam, aber sicher greift die Erkenntnis, dass gerade der wirklich freie Strommarkt, den sich die Europäische Union zum Ziel gesetzt hat, eine bessere Regulierung als derzeit nötig hat.

Die Kosten für die Gründerwelle des begonnenen dritten Jahrtausends werden zwar in die hunderte Milliarden Euro gehen, das Seltsame daran ist aber: Das Geld wäre durchaus vorhanden. Was fehlt, ist Sicherheit für die Investoren. Es fehlen einheitliche, klare, langfristige legistische Rahmenbedingungen. Die Belastungen von Produzenten und Konsumenten durch Umweltkosten steigen an. Die Verfahren dauern viel zu lang. Es fehlt schlicht an Berechenbarkeit.

Österreich wird - dank seiner großen Wasserkraftressourcen - nicht den ganzen Kraftwerkspark erneuern, wohl aber neue Wasser- und neue Wärmekraftwerke bauen müssen, will es nicht die Versorgung gefährden und/oder zum Importiand werden. Und Österreich muss sein überregionales Stromnetz nun endlich rasch ausbauen, um die bestehenden Engpässe auszuräumen und die Stromerzeugung im ganzen Land effizient einsetzen zu können.

Wir werden auch gut beraten sein, beim Kyoto-Ziel, bei der Umsetzung der EU-Wasserrahmenrichtlinie und bei der Ökostromförderung in Zukunft mit mehr Augenmaß vorzugehen.

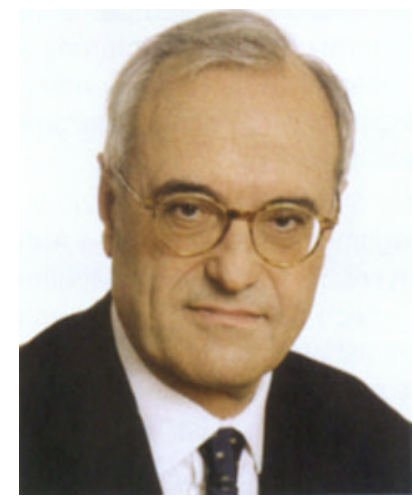

Hans Haider

Andernfalls steigt die Gefahr von Stromausfällen, und die von der Bevölkerung so hochgradig akzeptierte heimische Wasserkraft würde zunehmend an Bedeutung verlieren.

Ich gratuliere Prof. Dr. Günther Brauner, der nicht nur ausgewiesener Experte ist - sondern auch aufgrund großer Weitsicht - zu seiner Initiative für dieses hoch aktuelle Sonderheft der e \& i. Die Zeit für Entscheidungen ist reif. Wenn die Bedingungen stimmen, sind Visionen realisierbar. Es liegt ein großes Stück Arbeit vor uns allen, damit wir kommenden Generationen einen starken, wirtschaftlich gesunden, ökologisch nachhaltigen Energiesektor übergeben können. Beginnen wir jetzt damit!

\section{Dipl.-Ing. Hans Haider}

Generaldirektor des Verbund

Präsident von EURELECTRIC 